\title{
Comentario a Mesa redonda sobre las relaciones Chile-Perú
}

\section{Carlos Pareja Ríos*}

Agradezco al Instituto de Estudios Internacionales de la Universidad de Chile por organizar la mesa redonda sobre la relación entre Perú y Chile celebrada en Santiago en septiembre pasado. La discusión llevada a cabo en dicha ocasión ha significado un valioso aporte multidisciplinario para analizar la densidad de las vinculaciones entre nuestros dos países. Encuentros académicos de esa naturaleza siempre son bienvenidos y son más oportunos aún dentro del contexto actual en el cual se desenvuelve la relación peruano-chilena, puesto que solo mediante la discusión franca y abierta se facilita la comprensión de nuestra compleja relación vecinal.

Se me ha solicitado comentar sobre el contenido de dicha mesa redonda. El pedido me remite al tema de las percepciones expuesto en el encuentro por la periodista Jennyfer Salvo, ex agregada de prensa y cultura de Chile en Perú. Ella señala que las apreciaciones subjetivas de la realidad tienden a reflejar más la óptica del observador que las características mismas de la realidad observada. Debido a ello voy a enfocar mi atención en ciertos puntos mencionados en la discusión que merecen ser comentadas con algún detenimiento, ya sea porque dependen significativamente del punto de vista de observador o de la visión que se plantea sobre el futuro desarrollo de la relación bilateral. Mi objetivo es formular interpretaciones alternativas que contribuyan al enriquecimiento de un debate que nos es necesario, aun cuando esté marcado por diferentes sensibilidades y la diversidad de puntos de vista.

\footnotetext{
Embajador del Perú en Santiago.
} 
El sociólogo Sergio González centró su exposición en el período que transcurrió entre los años 1883 y 1929. A mi parecer, dichas décadas de continuos desencuentros constituyeron nuestra traumática y larga "postguerra» y fue el extenso período de tiempo dentro del cual se desarrollaron en Perú y Chile discursos nacionalistas de carácter antagónico. El clima de mutua discordia existente en ese entonces nutrió imaginarios que persisten siendo despertados en la actualidad con relativa facilidad. Sin embargo, las imágenes ancladas en el pasado no son inamovibles. Ellas se encuentran en constante proceso de redefinición, en función de la dinámica que adquiere la relación entre nuestros países en el presente y las visiones del futuro que se proyectan. Creo que la riqueza de la relación peruano-chilena no radica en recrear sensibilidades producto de nuestro legado histórico, sino en trabajar conjuntamente en la comunidad de intereses que compartimos, sobre la base de la visión de futuro que nos une por nuestra proyección común hacia el resto del mundo.

No obstante, en determinadas circunstancias la lectura de la historia refleja más las inquietudes o los temores del presente que lo ocurrido efectivamente en el pasado. Ello a veces nos lleva a suponer la existencia de racionalidades o motivaciones que no se condicen con los hechos. Me parece que ese es el caso cuando González sostiene que durante los años veinte del siglo pasado se consolidó en la cancillería peruana el objetivo «de no cerrar nunca el litigio fronterizo» con Chile.

A mi juicio, la evidencia demuestra que, por lo contrario, el Tratado de 1929 constituyó para Perú y Chile la solución definitiva de la prolongada disputa que sostuvimos en torno al límite terrestre. La inmediata demarcación física de la frontera terrestre reconfirmó la voluntad concordante de los dos países en concluir dicha disputa. A partir de entonces la línea de la frontera terrestre nunca ha dejado de ser considerada intangible por el Perú. Ello prueba que para el Perú y, por ende, para la cancillería peruana, el litigio sostenido con Chile sobre el límite terrestre quedó zanjado hace 80 años de manera perpetua, tal como corresponde jurídicamente a todo tratado limítrofe. De manera complementaria, los denominados «asuntos pendientes» de la ejecución del Tratado 
de 1929 nunca tuvieron naturaleza limítrofe y la cancillería peruana mantuvo interés persistente en resolverlos, tal como se logró finalmente con la firma del Acta de Lima de 1999. Debemos remarcar que estas negociaciones fallidas durante 70 años llegaron a buen término por la buena disposición de ambas cancillerías y la voluntad política de los gobiernos del Perú y Chile.

Considero por lo mismo que no es sostenible establecer un vínculo conceptual, tal como hizo González, entre la disputa territorial resuelta en 1929 y el caso sobre la delimitación marítima que está siendo visto hoy en la Corte Internacional de Justicia (CIJ). La primera concluyó de manera definitiva al culminarse la demarcación de la frontera terrestre. El caso seguido en La Haya gira en torno a la interpretación de las normas jurídicas desarrolladas décadas más tarde para la delimitación de los espacios marítimos, a la luz de la evolución del derecho del mar. Son dos temas que corresponden a ámbitos históricos y jurídicos distintos, sin otro nexo técnico que la lógica identidad geográfica que tiene que existir entre el punto de partida de los límites terrestre y marítimo.

Seguidamente, el ex agregado comercial de Chile en Perú, Cristián Maturana, presentó un interesante y detallado análisis de nuestra relación económica. Me parece muy pertinente su conclusión de que es necesario entender las necesidades del otro país para no contaminar la fructífera relación económica bilateral que nos es mutuamente beneficiosa. Aparte de la amplia información proporcionada por Maturana, que muestra el dinamismo de nuestra relación en los campos del comercio y la inversión, quisiera destacar la importancia y trascendencia de la creciente asociación empresarial y financiera entre nuestros dos países.

El progresivo aumento de las inversiones conjuntas, adquisiciones recíprocas de acciones empresariales y ventas de bonos en las bolsas de valores de uno y otro país, así como otras modalidades de operaciones efectuadas combinadamente por actores de ambos países, están creando una densa red de intereses económicos de propiedad binacional. Esa red binacional consolida de manera cualitativa la interdependencia económica y reconfirma que el crecimiento de nuestras respectivas economías constituye un interés común de mutuo beneficio. 
Adicionalmente, el inicio del flujo de inversiones significativas de capital peruano al mercado chileno ha inaugurado una nueva etapa de integración y cooperación empresarial. La creciente presencia de capital de origen peruano en Chile producirá beneficios similares a los que ha generado en Perú la inversión chilena al estimular el empleo y la producción nacional y, por ende, el crecimiento del PIB, y ha de reducir la asimetría mencionada por Maturana y otros autores. De modo paralelo, el consiguiente aumento de la presencia de ejecutivos y empresarios peruanos en Chile, y viceversa, facilita la necesaria comprensión mutua a la cual hizo alusión Maturana. La profundización de las relaciones de comercio e inversión es el motor de la integración y no hay que minimizar ni descuidar el papel fundamental que ha desempeñado la interdependencia económica en los procesos de integración a nivel mundial.

El director del diario El Mercurio de Valparaíso, Juan Pablo Toro, planteó un apretado recuento de los recientes desarrollos de nuestra relación bilateral. Al hacerlo sostuvo que tras la llegada de Alan García a la presidencia del Perú la presentación de la demanda marítima ante la CIJ «nos hizo volver de golpe a la realidad». Quisiera puntualizar al respecto que el presidente Alejandro Toledo planteó en agosto de 2002 al presidente Ricardo Lagos su intención de discutir sobre la delimitación marítima. Ello consta inclusive en la reseña de Carolina Bastías y Consuelo Hayden publicada en el último número de la revista Estudios Internacionales (p. 156), texto donde se indica que «en dicha oportunidad, la respuesta de Chile fue que el tema no estaba ni estaría en adelante en la agenda».

Toro mencionó luego una serie de variables históricas, económicas y de seguridad que, a su criterio, definen la relación bilateral. A partir de ello, afirmó que «un antagonismo latente hacia Chile» explicaría la decisión de recurrir a la CIJ para resolver la controversia marítima y opinó que dicha decisión nos expone «a entrar a un riesgoso juego de suma cero que probablemente afectará la relación bilateral en sus distintas dimensiones». Sostuvo asimismo que la imposibilidad de predecir el sentido de la sentencia del tribunal de La Haya introduce «un nivel de incertidumbre apreciable en la relación bilateral». 
No creo sinceramente que la noción de antagonismo sea la clave interpretativa para explicar la decisión acudir a la CIJ. La preexistencia de una discrepancia de interpretación jurídica sobre un tema de interés substantivo para los dos países motivó dicha decisión. Todo litigio judicial despierta ciertamente la confrontación de percepciones y sensibilidades, pero no hay que confundir causa con efecto. A mi modo de entender la incertidumbre y la tensión crecen mientras persisten las controversias y cesan más bien cuando ellas son resueltas de manera pacífica, de conformidad con el derecho internacional. La CIJ constituye en ese sentido la instancia jurídica internacional idónea para solucionar de manera imparcial y definitiva una controversia. Su decisión, inapelable por cierto, no ha de generar un «juego de suma cero", como teme Juan Pablo Toro, sino establecerá, con meridiana claridad, el marco jurídico vinculante que regulará de manera permanente el tema que hoy se encuentra en discusión.

Las experiencias recientes en Sudamérica confirman que la solución pacífica de las controversias utilizando los mecanismos que el derecho internacional pone a nuestro alcance ha desatado las fuerzas integradoras y de cooperación frenadas por la persistencia de discrepancias bilaterales. El caso peruano-ecuatoriano es un claro ejemplo de ello, pero más ilustrativo aún es el alto grado de integración alcanzado hoy por Chile y Argentina, una vez resueltas las diferencias limítrofes que subsistían entre ambos países. Es de esperar que las recientes sentencias internacionales sobre la delimitación marítima entre Nicaragua y Honduras y entre Guyana y Surinam, así como el caso en la misma materia entre Colombia y Nicaragua, reconfirmen dicha tendencia regional.

He mencionado previamente que la periodista Jennyfer Salvo presentó un persuasivo enfoque sobre las percepciones respecto a la relación entre Perú y Chile. Ella sostuvo que existe un divorcio histórico entre ambos países que dificulta la capacidad de entender nuestra relación bilateral. Sin embargo, quisiera subrayar el valor de dos hechos fundamentales que Salvo ha hecho notar. Ella constata que existe mayor rivalidad en los sectores más ideologizados de la sociedad, ajenos al ámbito económico y, de otro lado, que gracias al aumento de los negocios sostenidos entre ambos países y de 
la migración peruana a Chile está ocurriendo un encuentro cultural de vasta envergadura.

Considero que en efecto las visiones condicionadas fuertemente por la ideología tienden a facilitar la caricaturización del vecino, sobre la base de imágenes preconcebidas. En cambio, el pragmatismo confiere visiones más realistas y es el rasgo común del empresario que comercia con el país vecino o invierte en él y del individuo que emigra en búsqueda de mejores oportunidades. Las experiencias cotidianas del migrante, el empresario exportador o importador, el inversionista y el transportista internacional implican contactos directos con los ciudadanos del país vecino y esa intensa interacción social genera el conocimiento mutuo que disipa el temor y crea la confianza. Cabe mencionar que la fluidez de contactos también caracteriza la relación que existe en la actualidad entre los altos mandos de las Fuerzas Armadas de nuestros dos países y que ha fortalecido los lazos entre los institutos armados.

Creo que la intensificación de dicho tipo de interacción social es el elemento clave para analizar la construcción actual de las percepciones nacionales sobre el país vecino y la visión de futuro de nuestra relación vecinal. Las relaciones entre los ciudadanos peruanos y chilenos están definidas por los contactos efectivos entre los individuos, más que por las imágenes heredadas del pasado. En ese sentido, concuerdo con la opinión de Salvo de que la fuerza del encuentro cultural producido por el crecimiento de los lazos económicos y el aumento significativo de la migración está modificando, paulatinamente, el divorcio histórico ente las percepciones de ambos países. Visto en términos de larga duración, considero que dicho encuentro cultural tendrá efectos más profundos en el futuro desarrollo de la relación bilateral que las polémicas del presente o los conflictos del pasado.

La profesora Paz Milet incidió en su intervención en los factores que estima dificultan los avances en la agenda política o tradicional, en comparación con el ritmo constructivo de la agenda económica bilateral. Mencionó entre estos factores las imágenes nacionales contrapuestas, la influencia de la política interna, la multiplicidad de actores y la facilidad para la exacerbación de los conflictos. 
Dichos factores ciertamente traban con alguna frecuencia el desarrollo de las relaciones en el ámbito político, pero no son condiciones unívocas. Dichos factores también constituyen parte del entorno dentro del cual se desenvuelven positivamente las relaciones económicas entre ambos países. Lo que sucede es que en el campo económico y comercial los efectos negativos de los imaginarios colectivos ceden ante los intereses comunes, la influencia de la política interna se traduce en demandas para asegurar el apoyo efectivo de los dos gobiernos al fortalecimiento de la relación económica y la multiplicidad de actores tiene más bien un efecto positivo, en la medida que intensifica y amplía la red de vínculos bilaterales. El escalamiento de los conflictos también atañe a polémicas generadas por motivos de índole económica o comercial, pero en este ámbito prima la necesidad de preservar el beneficio mutuo.

A manera de colofón podría subrayar que los efectos de los factores subjetivos mencionados por la profesora Milet están determinados por la existencia o no de intereses comunes. En ese sentido, las trabas para profundizar la agenda política responden a la falta de identificación clara de los intereses políticos que nos son de beneficio mutuo fortalecer. Juan Pablo Toro menciona con acierto, por ejemplo, que debemos cooperar en nuevas áreas de importancia para ambos países como la lucha contra el narcotráfico. En términos similares, la fuerza integradora del proceso de interculturalización descrito por Jennyfer Salvo revela el beneficio político mutuo que significa fortalecer nuestro intercambio artístico y cultural. Adicionalmente, las acciones de los mecanismos de integración fronteriza redundan en beneficios concretos para los ciudadanos de los dos países, así como la cooperación efectiva en áreas sociales como la salud y educación, y en temas nuevos como la investigación científica, el intercambio académico y el desarrollo de circuitos turísticos conjuntos para el mejor conocimiento de nuestros países, entre otros. La situación es similar en relación con la multiplicidad de intereses políticos estratégicos que compartimos en función de nuestra proyección común a la región Asia-Pacífico y en el ámbito multilateral regional y global.

Considero que una visión constructiva de la relación peruano-chilena demanda distinguir los temas de interés co- 
mún en los cuales nos conviene mutuamente cooperar, de los temas de la agenda bilateral en los cuales discrepamos evidentemente. Al margen de las expresiones empleadas para calificar dicho enfoque, diferenciar intereses comunes de los divergentes es una necesidad que nace de la propia densidad de la trama de nexos que nos entrelaza. Asegurar la obtención de los beneficios concretos que nuestra cooperación activa puede generar responde a la interdependencia que crece en diversos campos de la relación vecinal.

Por último, el abogado Carlos Dettleff efectuó una exposición sobre los aspectos jurídicos de la controversia marítima entre Perú y Chile. Dettlef destacó que la demanda ante la CIJ está inscrita dentro de la institucionalidad legal regional creada, con el apoyo decidido de Chile y del Perú, entre otros países, con el objeto expreso de solucionar pacíficamente nuestras diferencias. Señaló que por eso no está de acuerdo con que el gobierno chileno se haya sentido agraviado cuando Perú presentó la demanda marítima. Creo que la construcción del andamiaje legal latinoamericano es un logro regional que merece ser destacado y que su consolidación radica precisamente en recurrir a los mecanismos de solución pacífica de controversias que hemos adoptado cuando es preciso hacerlo.

Dettlef indicó que sus inquietudes giraban más bien en torno a que al recurrir a un tribunal internacional se «pierde todo el control sobre las consecuencias». Considero respecto a ese punto que las consecuencias de un litigio judicial no radican en las decisiones de los jueces. Las consecuencias dependen del comportamiento de los Estados expresado en las acciones ulteriores ejecutadas por los gobiernos en cumplimiento de la sentencia internacional. Bajo esa perspectiva, concuerdo con expresiones efectuadas por distintas autoridades chilenas en el sentido de que el acatamiento a los fallos internacionales es la base de la estabilidad garantizada por el derecho internacional, que descansa, en última instancia, en la sujeción al derecho internacional moderno en la regulación de las relaciones interestatales. Esa es la razón de ser del sistema de normas internacionales que se ha venido desarrollando a nivel mundial, con el apoyo expreso del Perú y Chile.

Para finalizar quisiera reiterar que la ampliación de los espacios de discusión académica es una necesidad para com- 
prender mejor nuestra rica y compleja relación vecinal. El esfuerzo llevado a cabo por el Instituto de Estudios Internacionales recoge el espíritu analítico que debe primar para fortalecer una relación bilateral que responda a cabalidad al múltiple conjunto de esferas que entrelazan al Perú y Chile, y a la nutrida red de nexos e interés comunes que crece entre nuestros ciudadanos por la ineludible condición de países vecinos que define nuestra relación. 